\title{
SOBRE OS RECENTES ACONTECIMENTOS DA POLÍTICA BRASILEIRA: Leituras e Críticas a partir de Hannah Arendt
}

\author{
http://dx.doi.org/10.21527/2176-6622.2021.55.163-172
}

Recebido em: 21/6/2018

Aceito em: 26/5/2019

Luiz Antônio da Silva Bittencourt

Autor correspondente. Pontifícia Universidade Católica do Rio Grande do Sul - PUCRS e Universidad de Sevilla, Espanha. http://lattes.cnpq.br/1020223568689987. https://orcid.org/0000-0001-8653-5994. luizsofia@yahoo.com.br

Leandro José de Souza Martins Instituto Federal de Minas Gerais, Campus Ouro Branco. Ouro Branco/MG, Brasil.

\section{RESUMO}

Os acontecimentos trágicos pelos quais passa a sociedade nos últimos meses, provocam em cada pessoa uma pletora de sentimentos que pode ser resumida (uma entre tantas possibilidades) em três conceitos-chave: a indiferença, o medo e a indignação. O pensamento político de Hannah Arendt ante a conjuntura atual que o Brasil vem passando, torna-se interessante, principalmente pela forma como seu pensamento é construído. A experiência política moderna, muito criticada por Hannah Arendt, desvinculou-se de seus conceitos basilares, perdendo os fundamentos que foram erigidos ao longo dos séculos. A política, construção grega, sempre pautou-se pelo diálogo eloquente, pela persuasão. No contexto atual, no Brasil, é necessário um resgate da consciência política de coletividade para efetivar a democracia participativa.

Palavras-chave: Natureza humana. Política. Democracia.

\section{ON THE RECENT DEVELOPMENTS OF THE BRAZILIAN POLICY: READINGS AND CRITICS FROM HANNAH ARENDT}

\section{ABSTRACT}

The tragic events that society has been experiencing in the last few months provoke in each person a plethora of feelings that can be summarized (one among so many possibilities) in three key concepts: indifference, fear and indignation. The political thinking of Hannah Arendt in the face of the current conjuncture in which Brazil is passing becomes interesting, mainly because of the way her thinking is constructed. Modern political experience, much criticized by Hannah Arendt, dissociated herself from her basic concepts, losing the foundations that have been erected over the centuries. Politics, Greek construction was guided by eloquent dialogue, by persuasion. In the current context that is happening in Brazil, it is necessary a rescue of the political conscience of collectivity to effect the participatory democracy.

Keywords: Human nature. Policy. Democracy.

\section{SUMÁRIO}

1 Introdução. 2 A Política como condição fundamental da condição humana. 2.1 A vida ativa ante o totalitarismo. 2.2 A condição humana. 2.3 A ação na esfera da política. 3 A crise política brasileira sob a perspectiva de Hannah Arendt. 4 Considerações finais. 5 Referências. 


\section{INTRODUÇÃO}

Os acontecimentos trágicos pelos quais passa a sociedade nos últimos tempos, vêm provocando, em cada pessoa, uma pletora de sentimentos que pode ser resumida (uma possibilidade, entre tantas) em três conceitos-chave: a indiferença, o medo e a indignação.

Relativo à indiferença, aparecem muitos que, tendo conhecimento dos fatos, consideram-nos longe de sua vida privada e, uma vez que não os atingem, pouco importa falar sobre eles ou lhes dar maior atenção que a mera curiosidade ou informação evasiva de manchetes de jornais.

Aos mais sensíveis caberia um certo temor, não tanto porque se veem no centro das ameaças, mas porque presumem que elas prejudicarão seus negócios particulares e suas relações mais íntimas, especialmente as de caráter econômico. No meio destes, aparecem os que pensam que uma resposta é necessária, o que ocasiona, na maioria das vezes, condutas tão violentas quanto às que se quer combater.

Por fim, há os que se permitem questionar sobre a causa, o sentido, a finalidade de tamanha insegurança, o que faz despertar não só um pensamento sobre o que está acontecendo, mas sobre quem faz acontecer. Há uma mudança na questão que só a genuína indignação pode promover, uma vez que não foca mais nas dificuldades do mundo contemporâneo como externas ou completamente alheia, ou como autopoiéticas, pois se começa a pensar acerca dos sujeitos desta ação.

Em outras palavras, os que param e refletem profundamente sobre o que vem ocorrendo não se satisfazem nas análises de superfície e/ou impessoais. O próprio ato de indignar-se exige o questionamento sobre causas e agentes e entender-se como imbricado intimamente, ainda que não diretamente. Abre-se espaço para indagar sobre quem faz o que, sobre quem ganha ao fazer algo, sobre quem sofre por determinada violência, ameaça ou insegurança.

Os que pertencem ao grupo em questão, portanto, não projetam mais a resposta a um mundo de conceitos etéreos, mas clamam para algo mais pessoal e concreto, fazendo surgir tanto um sujeito quanto uma responsabilidade. Da pergunta usual e padrão "O que está acontecendo?", passa-se à indagação que desinstala e perturba: "O que estamos fazendo?".

Tal pergunta tornou-se o centro da obra político-filosófica de Hannah Arendt, especialmente em seus escritos "As origens do Totalitarismo" (1990) e "A Condição Humana" (2007). Tais obras levantam diversas possibilidades de reflexão, o que não será objeto neste ensaio. Dentre essas, destacam-se o colapso da moralidade, pressuposto central de qualquer totalitarismo, e as situações que enfatizam o ser humano como um ser condicionado, seguindo de um exame das condições mais permanentes da mesma condição humana e da vida ativa, quais sejam: o trabalho, o labor (fabricação) e a ação.

Seguindo as pegadas de Heidegger, a análise elaborada por Hannah Arendt rejeita qualquer desvio da experiência humana da perspectiva concreta da história e do mundo vivido, o que leva a um enfrentamento de situações críticas e catastróficas, como a Shoah judaica. Arendt não compartilha como elementos que venham metaforizar o caos da guerra e qualquer condição de vulnerabilidade da condição humana: antes, é preciso superar qualquer sobrevalorização de experiências de interioridade para encarar e superar os sintomas de certa "desmundialização" que tais experiências provocam.

Arendt, dessa forma, incita cada leitor a não escapar do caos provocado por eventos irreconciliáveis, motivando-o a partir de uma perspectiva concreta e existencial da necessidade e da liberdade, da política e da própria essência do humano. Por conseguinte, é preciso sempre considerar o "estar situado no mundo", no qual relações de comunicação (discurso e linguagem), poder e organização possibilitam a existência humana.

Quando questiona "O que estamos fazendo?", Hannah Arendt atinge de pleno o conjunto de vivências e costumes que, em nossos tempos, reduziram as relações humanas em uma rede consumerista ou em espaços que, de públicos (ou políticos), inflacionam-se com interesses privados e idiossincrasias. Tal contexto, que realiza uma deificação da tecnologia e das redes sociais, e que isola os sujeitos do espaço público de convivência e debate, esvazia, como consequência inevitável, a importância da política e do bem comum. 


\section{A POLÍTICA COMO CONDIÇÃO FUNDAMENTAL DA CONDIÇÃO HUMANA}

\subsection{A vida ativa ante o totalitarismo}

Na esteira do pensamento clássico grego, Hannah Arendt concebe a condição humana fazendo duas observações: não a coincide com as condições nas quais a vida foi dada ao homem; tampouco seria a condição humana sinônimo de natureza humana. Fundamentando-se em Agostinho, Hannah Arendt destaca que a natureza humana e os problemas a ela relativos parecem insolúveis, de difícil determinação. De tal modo, Arendt coloca a natureza humana como uma questão fundamental aos moldes da concepção agostiniana, que a compreendia como uma questão para si mesmo (quaestio mihi factus sum). Por sua vez, também as condições para a vida humana são incapazes de explicar o que é o homem, "[...] pela simples razão de que jamais nos condicionam de modo absoluto" (2007, p. 19).

De fato, de acordo com a própria autora,

O que proponho nas páginas que se seguem é uma reconsideração da condição humana à luz de nossas mais novas experiências e nossos temores mais recentes. É óbvio que isto requer reflexão; e a irreflexão - a imprudência temerária ou a irremediável confusão ou a repetição complacente de "verdades" que se tornaram triviais e vazias - parece ser uma das principais características do nosso tempo. O que proponho, portanto, é muito simples; trata-se apenas de refletir sobre o que estamos fazendo (ARENDT, 2007, p. 13).

Ora, conforme a autora, questionar-se sobre a ação é entender os processos que desembocam no esvaziamento do espaço político, identificado apenas como preocupação social. Além disso, a condição humana perde sua essência, pois ressalta-se o isolamento dos indivíduos que é, para Hannah Arendt, origem para qualquer tipo de totalitarismo (no qual qualquer faculdade de agir e participação se torna impossível).

Com efeito, a consequência do totalitarismo, "[...] a mais horrível forma de governo" (ARENDT, 1990, p. 51), é isolar o homem e deixá-lo como que perdido e solitário. O isolamento retrata-se também na pouca iniciativa de conviver com outrem e, em especial, com o diferente. O problema do isolamento não é apenas sociológico ou psicológico: Hannah Arendt não tem medo de afirmar que o grande mal que o isolamento produz é a destruição de qualquer aptidão política de cada pessoa.

Ou seja, o totalitarismo produz um isolamento que faz a esfera pública não apenas se esvaziar, mas perder totalmente seu sentido (ARENDT, 1990, p. 527). Aqui, acontece um fenômeno considerado pela autora como "um impasse": este, destrói o campo do político e possibilita o surgimento de radicalismos ou fundamentalismos que travestem a angústia produzida pelo isolamento.

Por sua vez, há também a angústia, a solidão, que ocorre no âmbito mais particular. É o que Hannah Arendt entendeu como "desenraizamento", como o sentimento de alguém que é abandonado, jogado ao léu. "Não ter raízes significa não ter no mundo um lugar reconhecido e garantido pelos outros" (ARENDT, 1990, p. 244). Vem, daí, a impossibilidade de convivência, do debate, da pluralidade e da diferença, do viver e do estar entre os homens, que, para Hannah Arendt, concordando com os romanos, são sinônimos entre si (inter homines esse) $)^{1}$.

Ante o totalitarismo, há de se propor uma postura que se paute como na polis grega, autêntica e legítima experiência política. Assim, por ver nos gregos antigos a essência e a esfera do político, Arendt resgata a compreensão da "Vida Ativa", e designa as atividades humanas fundamentais: labor², trabalho e ação. Justifica esta proposta, a própria autora, ao afirmar que, singularmente, as atividades da vida ativa "[...] corresponde uma das condições básicas mediante as quais a vida foi dada ao homem na Terra" (ARENDT, 2007, p. 15); “[...] a vida humana na medida em que se empenha ativamente em fazer algo".

O que, portanto, faz o isolamento e o desenraizamento é o contrário daquilo que deve ser a preocupação fundamental da política: a convivência. Nas clássicas palavras de Celso Lafer: Politicamente, não existimos isolados, mas coexistimos. Daí, a tensão entre a filosofia na qual o pensar é a dualidade do diálogo coerente do eu consigo mesmo - e a política, na qual a pluralidade exige um estar sempre ligado aos outros, pois se podemos pensar por conta própria, só podemos agir em conjunto (Posfácio in ARENDT, 2007, p. 348).

2 Labor, como substantivo, "[...] não designa o produto final, o resultado da ação de laborar. Permanece como substantivo verbal, uma espécie de gerúndio. Por outro lado, é da palavra correspondente a trabalho que deriva o nome do próprio produto", explica Arendt (2007, p. 91). 


\subsection{A condição humana}

O que consistiria, portanto, a condição humana? Para a autora, falar de condição humana presumir-se-iam as três categorias básicas, tendo cada qual sua qualidade: labor, trabalho e ação. Além disso, há de se destacar que, para Hannah Arendt, há outras três grandes abordagens para entender a condição humana: a primeira, de que a condição humana corresponde à pluralidade; ao mesmo tempo, a condição humana leva em conta a singularidade; e por fim, que todos os aspectos da condição humana têm alguma relação com a política, da qual a pluralidade é a conditio per quam e a ação (práxis) a atividade política por excelência.

Hannah Arendt define o labor como as específicas atividades inerentes ao corpo humano no que se refere à exigência de manter-se vivo. Seriam, portanto, processos biológicos, metabolismos, atividade corporal que se fazem espontaneamente. O labor é a condição de vida comum a homens e a animais sujeitos à necessidade de prover a própria subsistência. Por conseguinte, Hannah Arendt atribui a denominação de homo laborans.

Por sua vez, cabe compreender o termo trabalho como uma produção do homem, algo que se faz externa e artificialmente. $\mathrm{O}$ que se produz, o que é fruto/consequência do trabalho, é diferente do ambiente natural e que transcende à vida individual. Tudo é feito para se adaptar à vida do homem, que, como age como um construtor do mundo, é denominado homo faber. De acordo com a pensadora, tal fabricante, exercendo um trabalho de erigir um mundo, é um ser pragmático que instrumentaliza tanto objetos quanto pessoas para, por meio delas, conseguir fins diferentes e que lhes são mais convenientes.

Hannah Arendt chama a atenção para algo que, em nossos dias, parece corriqueiro: o homo faber facilmente relaciona-se com tudo como se estivesse em um mercado (2007, p. 221), realizando, constantemente, barganhas, e fazendo dessa negociação o objetivo principal de sua atividade.

Essas coisas produzidas pelo homem para a troca derivam da violência exercida por ele contra a natureza mediante a transformação desta em artifícios que depois serão trocados no mercado, visando a acumulação de riqueza. A esse ser que transforma a natureza chamamos homo faber, observando que esse fabricante do mundo utiliza-se das categorias de meios e fins: ele imagina o objeto, destrói a natureza para construí-lo e depois o leva ao mercado para trocá-lo, adquirindo riqueza que o levará a produzir novos objetos [...] Os instrumentos e as coisas fabricadas criam para o fabricante um mundo comum com os outros: os objetos de seu trabalho são expostos no mercado de trocas e esse mercado reflete uma esfera pública distorcida pela relatividade dos valores (FIORATI, 1999, p. 55-56).

Por fim, Hannah Arendt fala da ação. Esta diferencia-se tanto do labor quanto do trabalho e poderia ser conceituada como "Atividade exercida entre homens, independentemente da produção de coisas ou da manutenção da vida, devido ao fato de que os homens e o homem vivem na terra e habitam o mundo" (ARENDT, 2007, p. 15).

É na ação que se depreende o conceito mais pleno da condição humana. De acordo com Oliveira (2012), reside na condição humana

[...] o que seria mais essencial à sua humanidade, bastando, portanto, chamá-lo simplesmente de homem um ser que na ação nada mais exprime senão ele mesmo (...) se o animal laborans é regido pela "necessidade", e se o homo faber age de acordo com critérios de !utilidade! e "instrumentalidade", o homem arendtiano está destinado a um destino (sic) mais nobre: às ociosas ações e opiniões que constituem e esfera dos negócios humanos" (p. 59).

Deste modo, a condição humana da ação é a pluralidade. Tal pluralidade leva em conta a centralidade da palavra e do discurso e possui o duplo aspecto de igualdade e da diferença. Mediante o discurso e pela ação, cada homem será distinto, mas não como isolado ou sem relação. A distinção, aqui, apresenta o aspecto da singularidade, ou seja, a capacidade de se perceber como único, mas relacional, sem cair na compreensão de um indivíduo humano monadicamente isolado em qualquer das manifestações de sua existência. 
Assim, na pluralidade, não há Homem, mas homens ("ao fato de que os homens, e não o Homem, vivem na Terra e habitam o mundo"), evitando qualquer manifestação metafísica sem levar em conta a comunidade política na qual os homens inter-relacionam-se. Em outros termos, "[...] a pluralidade é a condição da ação humana pelo fato de sermos todos os mesmos, isto é, humanos, sem que ninguém seja exatamente igual a qualquer pessoa que tenha existido, exista ou venha a existir" (ARENDT, 2007, p. 16).

Com a pluralidade humana, a condição de existência do homem sobre a terra abre-se ao espaço do político. Afinal, se há uma natureza que torna todos iguais, há de se atentar que, ao mesmo tempo, cada qual apresenta diferenças e variações em seus caracteres individuais. A fim de preservar tais diferenças, faz-se necessária a constante presença e continuado diálogo com os outros.

Na pluralidade, há de se destacar a singularidade, pela qual os homens são iguais sem serem únicos; são diferentes sem serem incompatíveis. A alteridade, por conseguinte, é aspecto fundamental da pluralidade.

Se não fossem iguais, os homens seriam incapazes de compreender-se entre si e aos seus ancestrais, ou de fazer planos para o futuro e prever as necessidades das gerações vindouras. Se não fossem diferentes, se cada ser humano não diferisse de todos os que existiram, existem ou virão a existir, os homens não precisariam do discurso e da ação para se fazerem entender (...) Só o homem é capaz de exprimir essa diferença e distinguir-se; só ele é capaz de comunicar a si próprio e não apenas comunicar alguma coisa. No homem, a alteridade, que ele tem em comum com tudo o que existe, e a distinção, que ele partilha com tudo que vive, tornam-se singularidade, e a pluralidade humana é a paradoxal pluralidade de seres singulares (ARENDT, 2007, p. 188-189).

Haverá, destarte, que se livrar do perigo de ideias e posturas que sacrifiquem valores em nome do animal laborans. A ação consiste na vida livre do labor e do trabalho (pois o homo faber, segundo os antigos, tinha como principal interesse "o seu ofício e não o mundo público"), e é continuamente voltada para o horizonte da liberdade.

\subsection{A Ação na Esfera da Política}

$\mathrm{Na}$ ação política as pessoas interagem sem violência, nem pró nem contra, mas "com" [vivência]. Não há, nessa relação, mediação das coisas ou matérias: por viverem na Terra e habitarem o mundo juntos, os homens são capazes de colocar a si mesmos, mediante a ação e o discurso, em relacionamento uns com os outros. "Todas as atividades humanas", afirmar Hannah Arendt, "são condicionadas pelo fato de que os homens vivem juntos; mas a ação é a única que não pode sequer ser imaginada fora da sociedade dos homens" (SILVA, 2011, p. 5). Conclui-se de tudo isso que todos os aspectos da condição humana têm alguma relação com a política.

A política é uma ergon, como Aristóteles já havia identificado e, portanto, Hannah Arendt salienta que Aristóteles tem, em sua filosofia política, uma clara consciência do que está em jogo na política, ou seja, nada menos que a ergon tou anthropou ("a obra do homem" enquanto homem), não enquanto animal ou fabricante de coisa. Ademais, a ação política seria aquela que exclui o que seria necessário ou útil para abrir-se ao campo das atividades superiores, o que Arendt chamará de "[...] ociosas ações e opiniões que constituem a esfera dos negócios humanos" (ARENDT, 2007, p. 242).

Tal centralidade da ação, entretanto, esvaziou-se na Modernidade quando a ação cedeu lugar ao trabalho. Consequentemente, a exclusão da ação reduziu o alcance e as propriedades da esfera pública: onde os homens mostravam "quem" eram passa a ser meramente um mercado, no qual eles se destacam como simples fabricantes de coisas (homo faber), ou em sua animalidade, envolvidos que estão no ciclo do processo vital. Conforme Arendt (2007),

A sociedade é a forma na qual o fato da dependência mútua em prol da subsistência, e de nada mais, adquire importância pública, e na qual as atividades que dizem respeito à mera sobrevivência são admitidas em praça pública [...] A esfera social, na qual o processo da vida estabeleceu o seu próprio domínio público, desencadeou um crescimento artificial, por assim dizer, do natural; e é contra esse crescimento [...] que o privado e o íntimo, de um lado, e, de outro, o político (no sentido mais restrito da palavra) mostram-se incapazes de oferecer resistência (p. 56-57). 
Por isso que a ação, por suas características, revelou-se inadmissível para o homem moderno. Hannah Arendt afirma que "[...] a era moderna estava tão decidida a excluir de sua esfera pública o homem político, ou seja, o homem que fala e age, quanto a antiguidade estava interessada em excluir o homo faber" (ARENDT, 2007, p. 199). A política não se dá no homem, mas entre os homens, na esfera pública, quando estes se revelam mediante a ação e o discurso, demonstrando, também, sua "coragem" ao abandonarem seu esconderijo para mostrar quem são.

Os homens sempre souberam que aquele que age nunca sabe exatamente o que está fazendo; que sempre vem a ser "culpado" de consequências que jamais desejou ou previu; que, por mais desastrosas e imprevistas que sejam as consequências do seu ato, jamais poderá desfazê-lo; que o processo por ele iniciado jamais termina inequivocamente num único ato ou evento, e que seu verdadeiro significado jamais se revela ao ator, mas somente à visão retrospectiva do historiador, que não participa da ação. Tudo isto é motivo suficiente para que o homem se afaste, desesperado, da esfera dos negócios humanos e veja com desdém a capacidade humana de liberdade que, criando uma teia de relações entre os homens, parece enredar de tal modo o seu criador que este lembra mais uma vítima ou paciente que o autor e agente do que fez (ARENDT, 2007, p. 245).

Haveria alguma solução para superar esta condição humana reduzida ao labor para retornar à sua verdadeira essência? Para Hannah Arendt, um caminho se faz possível: a perspectiva da liberdade, pela qual o homem se reconhece naquilo que é mais próprio. O que corresponde ao homem livre é o fato de ele sempre ser um começo, uma vez que seu agir (enquanto ação) é sempre um "[...] tomar a iniciativa, iniciar (como indica a palavra grega archein, 'começar' [...]" (ARENDT, 2007, p. 190).

Arendt reinterpreta a afirmação de Agostinho: "[...] o homem é livre porque ele é um começo" (ARENDT, 2007, p. 190). Para a autora, a liberdade não está relacionada exclusivamente com a faculdade da vontade, mas ao princípio de algo que nunca existiu no mundo antes. Nesse sentido, é porque o homem é um começo que ele pode introduzir algo de novo no mundo, ou seja, mudar a realidade existente.

\section{A CRISE POLÍTICA BRASILEIRA SOB A PERSPECTIVA DE HANNAH ARENDT}

Não é impossível tentar pensar a crise política que assola o Brasil na perspectiva de Hannah Arendt. Neste panorama, percebe-se que há fortemente um discurso de tentativa de dominação de um grupo pequeno, de um grupo que detém o poder econômico (SAFATLE, 2015).

De fato, a realidade vivenciada no Brasil, hodiernamente, é a retratada por Hannah Arendt em "Origens do Totalitarismo". As inverdades e/ou ideias apresentadas de modo ambíguo nas propagandas de televisão conduziram à formação de um pré-juízo de que tudo estava caminhando mal, de que a economia apresentava-se em derrocada, e que apenas um determinado governo estaria, em todas as instâncias, envolvido em corrupção.

De acordo com Lafer (1979, p. 47), "De fato, o totalitarismo, ao monopolizar a expressão da verdade procura através da propaganda e do controle dos meios de comunicação assegurar uma versão oficial dos fatos, desfigurando-os para adequá-los à sua ideologia".

Nesse sentido, não é novidade para qualquer brasileiro o tamanho de atenção que a mídia vem dando à política nos últimos anos. Especificamente no último governo, diversos telejornais dedicavam-se quase que exclusivamente a transmitir notícias, suspeitamente manipuladas e com viés tendencioso, sobre os problemas que o governo enfrentava, principalmente a partir do momento em que surgiram os primeiros pedidos de afastamento da chefe do Executivo.

Houve o surgimento de muitas denúncias e uma crescente percepção de que havia uma enorme manipulação dos fatos, muitas vezes tentando tornar dados imprecisos ou pouco fundamentados em uma verdade.

Dentre tantas denúncias, surge a redação de Carlos Eduardo Martins (2017), na qual o autor enumera nove teses ${ }^{3}$ que evidenciam a crise política brasileira atual. Destas teses, serão tomadas, aqui, duas, cuja interpretação vem ao encontro da conjuntura atual.

\footnotetext{
Mais informações, conferir em: https://blogdaboitempo.com.br/2017/05/29/notas-sobre-a-crise-politica-brasileira/. Acesso em: 29 jul. 2016.
} 
A primeira tese elencada pelo autor, afirma que houve um golpe e que este foi orquestrado em forma preventiva, uma vez que os anos do governo do Partido dos Trabalhadores conduziram ao fortalecimento de movimentos sociais, dando voz a pequenos grupos. "O golpe de Estado de 2016 foi preventivo e dirigido contra a crescente capacidade de organização dos trabalhadores e o protagonismo dos movimentos sociais. Este protagonismo se expressou em várias dimensões" (MARTINS, 2017).

Nessa dimensão, Bittencourt e Schuvartz (2017) [op. cit. DELGADO (2015)] afirmaram que houve uma expressiva reconstrução do primado do trabalho no Brasil. As políticas de inclusão e de modernização dos direitos trabalhistas e os avanços no conceito de trabalhador, foram fatores determinantes. De fato, no período de 11 anos mais de 20 milhões de empregos formais foram formalizados, o que representa avanço cultural de um lado e, de outro, aumenta o investimento do empregador no custeio de encargos sociais.

Nesse sentido, conforme Martins (2017), a capacidade de organização dos trabalhadores e a força dos movimentos sociais vinha, em verdade, representando um perigo para a classe econômica dominante. Não agradava a proposta das políticas do governo do Partido dos Trabalhadores, que caminhavam em sintonia para reconstruir uma nova realidade. Por isso, essa classe iniciou um movimento de tentativa de desconstrução dessa política mediante propagandas, muitas vezes falseadas de uma crise em proporções surreais.

Os movimentos sociais, ocorridos a partir do ano de 2013, tendo como protagonistas jovens que almejavam ampliação das políticas sociais de inclusão, impulsionaram a articulação do movimento de derrocada do governo popular trabalhista. Com as eleições de 2014, claramente os ataques midiáticos se intensificaram.

A segunda tese sustentada por Martins (2017) é a de que o golpe parlamentar foi orquestrado por um grupo empresarial econômico de entidades patronais. A adesão foi forte e com a ajuda de grandes redes de televisão nacional, que passaram a dedicar horas e mais horas nos telejornais em comentários e notícias tendenciosas. O que se viu foram noticiários distorcidos objetivando manipular a grande massa, o que foi determinante. Martins sustenta que

Precedeu ao golpe de 2016, a forte adesão das principais entidades patronais brasileiras (FIESP, FIRJAN, CNI, ABIMAQ, FEBRABAN e Sociedade Rural Brasileira), e seu principal braço midiático de organização ideológica (Rede Globo), à implementação de um programa de austeridade fiscal e monetária num contexto de queda dos preços das commodities e do investimento privado, o que obrigatoriamente levaria à forte depressão econômica, com drástica queda da arrecadação fiscal e exponencialização dos pagamentos de juros, implicando em forte crise financeira do Estado (2017).

\section{E continua:}

A queda do governo Dilma possibilitou avançar em temas da agenda de reformas neoliberais que encontrariam resistência nos governos petistas como o congelamento dos gastos públicos primários por 20 anos, a reforma trabalhista, a lei de terceirizações, a reforma da Previdência, o fim das políticas industriais do BNDES, a retomada de privatização de empresas ou a eliminação do monopólio da Petrobrás e da política de conteúdo nacional para investimentos no Pré-Sal. Por meio das políticas de elevação da superexploração do trabalho e da atração de capital estrangeiro procurava-se compensar a restrição de gastos públicos primários e retomar o dinamismo econômico, associando-o ao aumento das taxas de exploração, da lucratividade e do investimento (2017).

O resultado do golpe parlamentar a sociedade toda tem experenciado. As políticas adotadas a partir do governo de Michel Temer são, para muitos setores da sociedade, pautadas por um modelo de desconstrução, que atinge de morte todo um esforço empregado para gerar maior inserção social da população brasileira.

Como pensar, no entanto, toda essa estrutura política brasileira a partir de Hannah Arendt?

De fato, encontrar uma resposta para essa indagação não é tarefa tão simples, uma vez que é preciso repensar a própria condição humana. É tentar entender a própria condição humana a partir do modelo estrutural brasileiro, até porque, como bem leciona Adeodato (1989, p. 114): 
A condição humana tampouco se confunde com a natureza em geral, ela "...compreende algo mais que as condições nas quais a vida foi dada ao homem.", inclui também objetos resultados da influência humana sobre seu ambiente, criações artificiais como a roda de telescópio, a família e o Estado, a positivação do direito e a influência de Aristóteles: tudo aquilo com que os homens entram em contato passa a condicionar sua existência.

A experiência política moderna, muito criticada por Hannah Arendt, desvinculou-se de seus conceitos basilares, perdendo os fundamentos que foram erigidos ao longo dos séculos. A política, construção grega, pautava-se pelo diálogo eloquente, pela persuasão. A palavra era a força. Na atualidade, entretanto, houve o desvinculamento da ação e do discurso. "Ser político, viver numa polis, significava que tudo era decidido mediante palavras e persuasão, e não força e violência" (ARENDT, 2004, p. 31). Nesse sentido, não dá para pensar no ser político em sua base histórica. No Brasil, há a prevalência do discurso do capital econômico.

A razão de ser da política e o seu sentido é a liberdade: se os homens não tivessem a capacidade de se relacionar livremente, não haveria a política; e se os homens não tivessem a potencialidade de estabelecer sua própria realidade, a política não teria sentido algum. A política, porém, é inter-relação, é con-vivência. No nascimento de cada homem a possibilidade de um novo começo é reafirmada, pois cada novo ser humano que nasce renova potencialmente o mundo. Esta é a esperança para a superação do mero labor ou trabalho e para o resgate da verdadeira condição humana, na qual discurso e ação integram-se como revelação da verdade do homem e do mundo.

[...] a qualidade reveladora do discurso e da ação vem à tona quando as pessoas estão com as outras, isto é, no simples gozo da convivência humana, e não "pró" ou "contra" as outras. Embora ninguém saiba que tipo de "quem" revela ao se expor na ação e na palavra, é necessário que cada um esteja disposto a correr o risco da revelação [...] (ARENDT, 2007, p. 192).

O que se percebe no Brasil, atualmente, é que se tenta criar uma ideologia de dominação a partir da tentativa de demonstrar que o caminho que se tem tomado é o melhor: o de resgate do crescimento de estabilização da economia e da geração de novos empregos. As políticas reformistas, por meio da propaganda de manipulação, são apresentadas como o único caminho capaz de gerar, no Brasil, a confiança do capital econômico e a retomada do crescimento.

Essa ideologia que está sendo construída, todavia, é falseada. Percebe-se, nesse discurso, matrizes totalitaristas, mas com cunho pós-moderno. Como, para Hannah Arendt, para se falar em totalitarismo precisam estar presentes dois pilares - a ideologia e o terror -, verifica-se que o discurso atual se embasa nesses dois fundamentos.

A nova ideologia que está sendo instituída tenta mostrar que as reformas estruturais apresentadas são as melhores e necessárias. Retira-se direitos conquistados a duras penas por intermédio das lutas sociais e sindicais ocorridas ao longo das décadas precedentes e, ao mesmo tempo, tenta-se imprimir o terror de que se não reformar não haverá outra solução senão o colapso, o aumento da pobreza, do desemprego, da impossibilidade de sustentação do sistema previdenciário, dentre outros.

Para Chaves (2009), essa tentativa de impressão de um totalitarismo mediante o discurso busca gerar superfluidade nos homens e gera manipulação de massa.

De outro lado, ainda é possível perceber que há, no Brasil, o que Hannah Arendt (2004, p. 83) chama de culpa coletiva. De fato, percebe-se que a sociedade brasileira tem tomado uma postura de indiferença com as mudanças ocorridas. As diversas manifestações sociais têm alcançado uma aderência mínima. É como se as mudanças que estão acontecendo não atingissem a grande massa. A manipulação midiática tem sido tão expressiva que tenta sufocar os movimentos de resistência.

Pensar a política a partir da constatação de Hannah Arendt (2002, p. 21) como "A política baseia-se na pluralidade dos homens. [...] A política trata da convivência entre diferentes. Os homens se organizam politicamente para certas coisas em comum [...]", é o que precisa ser feito no Brasil. O pensar diferente, a convivência com o diferente, é algo ainda utópico na nossa realidade. Somos herdeiros da tradição portuguesa de 
dominação. Poucas famílias detêm o poder econômico e, por isso, este possui o poder de dominação. Assim, a política precisa redescobrir sua função precípua, gerar bem-estar social e não estar a serviço da minoria dominante.

A ausência de diálogo no âmbito político é movimento que causa estranheza. 0 discurso erigido pelos detentores do poder de governança é aquele que tenta demonstrar que tudo se caminha na mais perfeita harmonia. As crises de corrupção envolvendo agentes políticos, mesmo sendo constantes, têm tomado uma dimensão mínima, uma que a proposta que gerou o afastamento da presidente Dilma não é mais discutida.

De fato, insta destacar a apatia, a falta de discurso sério e debate, a ausência do espaço político e de ver a importância da república (res publica). A população brasileira, em geral, tem adotado uma postura de afastamento e apatia pela coisa pública. A relação de pertença à comunidade política não tem surtido efeito, posto que não se verifica a manifestação pública do povo brasileiro ante os acontecimentos, diferentemente do que se percebe na Venezuela.

\section{CONSIDERAÇÕES FINAIS}

Ao compulsar o pensamento político de Hannah Arendt, constata-se que a condição do homem é aquela consistente em ser-no-mundo, ou seja, o homem está inserido num mundo real, factual, permeado por normas emanadas visando à convivência.

Nesse sentido, a política assume uma posição importante na vida das pessoas, pois sua função de gerar o bem-estar social deve ser pautada pelos princípios do diálogo e do discurso.

A teoria da natureza humana, na perspectiva de Hannah Arendt, é aquela construída sob os três pilares: trabalho, obra e ação. Pela ação o homem constrói o discurso político, fundamentado na liberdade e na igualdade, sendo a política uma função da sociedade. No pensamento da autora, percebe-se que é necessário tentar reconquistar as bases da política por meio do pensamento dos antigos filósofos, para se ter a real noção do conceito de política, construída mediante o discurso, e da persuasão e não da força.

Ademais, o que causa mais estranheza, e foi constatado por Hannah Arendt quando das atrocidades advindas do nazismo, é a questão da apatia da população. No Brasil, embora tenha havido (e ainda estão em trâmites) diversas mudanças expressivas nos direitos que foram conquistados por meio de muitas lutas, a apatia da população brasileira é assustadora. Os grandes prejudicados mantêm-se em silêncio, e a grande população tomou uma postura de que tudo está bem, em ordem.

\section{REFERÊNCIAS}

ADEODATO, João Maurício Leitão. O problema da legitimidade: no rastro do pensamento de Hannah Arendt. Rio de Janeiro: Forense Universitária, 1989.

ARENDT, Hannah. As origens do totalitarismo: totalitarismo, o paroxismo do poder. São Paulo: Companhia das Letras, 1990.

ARENDT, Hannah. A condição humana. Trad. Roberto Raposo. Posfácio Celso Lafer. 10. ed. Rio de Janeiro: Forense Universitária, 2007.

ARENDT, Hannah. O que é política? 3. ed. Rio de Janeiro: Editora Bertrand Brasil, 2002.

ARENDT, Hannah. Responsabilidade e julgamento. 1a reimp. São Paulo: Companhia das letras, 2004.

BITTENCOURT, Luiz Antônio da Silva; SCHUVARTZ, Neiva. Direito ao trabalho digno: uma releitura dos direitos fundamentais. In: TEODORO, Maria Cecília Máximo et al. Tópicos contemporâneos de Direito do Trabalho: reflexões e críticas. Belo Horizonte: RTM, 2017. p. 247-258. V. 2.

CHAVES, Rosangela. A capacidade de julgar: um diálogo com Hannah Arendt. Goiânia: Cânone Editorial, 2009.

CORREIA, A. (org.). Hannah Arendt e a condição humana. Salvador: Quarteto, 2006.

DELGADO, Maurício Godinho. Capitalismo, trabalho e emprego: entre o paradigma da destruição e os caminhos da reconstrução. 2. ed. São Paulo: LTR, 2015.

FIORATI, Jete Jane. Os direitos do homem e a condição humana no pensamento de Hannah Arendt. In: Revista de Informação Legislativa, Brasília, v. 36, n. 142, p. 53-64, abr./jun. 1999.

LAFER, Celso. Hannah Arendt: pensamento, persuasão e poder. São Paulo: Paz e Terra, 1979. 


\section{Direito: Debate}

MARTINS, Carlos Eduardo. Nove teses sobre a crise política brasileira. 2017. Disponível em: https://blogdaboitempo.com. br/2017/05/29/notas-sobre-a-crise-politica-brasileira/. Acesso em: 29 jul. 2017.

OLIVEIRA, Luciano. 10 lições sobre Hannah Arendt. Petrópolis: Vozes, 2012.

SAFATLE, Vladimir. O circuito dos afetos: corpos políticos, desamparo e o fim do indivíduo. São Paulo: Cosac Naify, 2015.

SILVA, Moisés Rodrigues da. O homem e a política em A condição humana. In: Revista Estudos Filosóficos, n. 6, 2011 - versão eletrônica - ISSN 2177-2967 DFIME - UFS - São João Del-Rei-MG. p. 1-18. Disponível em: http://www.ufsj.edu.br/revistaestudosfilosoficos. Acessado em: 24 jul. 2017. 